\title{
Wind-PV-Energy storage system coordinated optimization control based on variable weight value self-adaptive filter.
}

\author{
Li-Dexin $^{1, a}$, Lv-Xiangyu ${ }^{1, b}$, Han-Xiaojuan ${ }^{2, c}$ \\ ${ }^{1}$ Status Grid Jilin Electric Power Company Limited Electric Power Research Institute, \\ Changchun, 132012, China \\ ${ }^{2}$ North China Electric Power University, Beijing, 102206, China \\ aemail: lidexin0323@163.com, bemail:caulxy@163.com, cemail:xuefeichang@163.com \\ demail:wmhxj@163.com
}

Keywords: Wind-PV-Energy storage system; Optimization control; Variable weight value; Self-adaptive filter

\begin{abstract}
For smoothing Wind-PV-Energy storage system output power fluctuation problem, this paper proposed Wind-PV-Energy storage coordinated control method based on variable weight self-adaption filter, considering the Wind-PV system volatility constraint conditions and the energy storage system SOC. With index of the SOC balance of energy storage system and power grid volatility as constraint condition real-time adjusting weights and filter bandwidth of weighted filtering algorithm. With the volatility constrain condition, it used energy storage coordinating the balance between Wind-PV system and grid, reduced the energy storage output frequency and the using time, extended the service life of the energy storage system, improved the economic benefit of Wind-PV-Energy storage joint generation systems.
\end{abstract}

\section{Introduction}

Wind power and PV Power have volatile, intermittent and anti peaking characteristics [1]. Wind and solar power, whether in a long time or short time, present stronger complementary characteristics. If the grid configure properly capacity of energy storage system , it can not only stabilize fluctuations of wind and PV power accessing to grid, reduce the impact on the power system, ensure the reliability of power supply but also can reduce the reserve capacity of power system, improve the efficiently operation and the ability of accepting renewable energy. In the premise of full using wind and solar power, how to realize the power coordination control between the wind farm, PV power station and energy storage system has become a key point research of wind-PV — energy storage system joint power generation technology, and also is one of the main research directions .

Currently research on wind-PV— energy storage system coordinating optimization control are mainly concentrated in smooth control of power output and tracking control these two aspects. In this field domestic and international scholar have obtain certain research results. Literature [2] have study the effectiveness which the energy storage system is used to control wind power fluctuation smooth and using low-pass filter principle controlling wind power certain frequency component smooth. Literature [3][4][5] have proposed wind-PV— energy storage system smoothing control strategy which considering the fuzzy control. It has self-adaption adjusted wind power smooth based on intelligent algorithm, and optimize the control strategy of the energy storage system to stabilize Wind - PV joint power generation system output fluctuations. Literature [5] according to operating characteristic of Wind-PV-Energy storage system , have proposed different coordinated control method of maximum power, load power tracking and battery charging and discharging control.

This paper proposed Wind-PV-Energy storage coordinated control method based on variable weight self-adaption filter, considering the Wind-PV system volatility constraint conditions and the energy storage system SOC. It used energy storage coordinating the balance between Wind-PV 
system and grid, reduced the energy storage output frequency and the using time, extended the service life of the energy storage system, improved the economic benefit of Wind-PV-Energy storage joint generation systems.

\section{Wind-PV power system output smoothing based on the weighted moving average filtering}

\section{Algorithm weighted moving average filtering}

Moving average method is a main method in time series prediction method and mainly used for the analysis of the market economy which is stable and a little change in the short term trend in the economic.

Formula 1 of moving average method is shown below.

$$
\mathrm{y}_{\mathrm{t}+1}=\frac{1}{\mathrm{n}} \sum_{\mathrm{i}=0}^{\mathrm{n}-1} \mathrm{y}_{\mathrm{t}-\mathrm{i}}
$$

Type: $\mathrm{t}$ is the current time; $\mathrm{yt}-\mathrm{I}$ is the real value of $\mathrm{t}-\mathrm{I}$ period; $\mathrm{n}$ is mobile number; $\mathrm{yt}+1$ is the predictive value of $t+1$ period. With the increase of $t$, this method can eliminate the irregular change, but produces the delay phenomenon which present expected value fall behind the actual trend. In this regard, we can use the improved weighted moving average method. The core of the method is assigned the larger weight for recent real value, and assigned the less weight for long-term value. Formula 2 is shown below.

$$
\mathrm{y}_{\mathrm{t}+1}=\frac{\sum_{\mathrm{i}=0}^{\mathrm{n}-1} \mathrm{w}_{\mathrm{i}} \mathrm{y}_{\mathrm{t}-\mathrm{i}}}{\sum_{\mathrm{i}=0}^{\mathrm{n}-1} \mathrm{w}_{\mathrm{i}}}
$$

Type: wi $>$ wi-1, wi is the weight.

On the basis of the formula (2), according to the trend of the Wind -PV power and the fluctuation, we have distributed the trend weight $\beta(n)$ on Wind -PV power at each moment, which is shown in Formula 3.

$$
\beta(n)=1-\theta+\frac{\theta n}{N}
$$

Type: $\theta$ is trend slope, $\theta \in(0,0.5)$, the greater the value indicated the recent scenery power proportion is larger. $\mathrm{N}$ is number for moving average items (This article mentioned the filter bandwidth $\mathrm{T}$ ). Target values of $\mathrm{n}$ time should pay attention to the recent trend of wind power output power, relative to weaken its further efforts in the past. So $\beta(n)$ is increasing function.

Set up the smooth target power at t0 is weighted average value for the past $\mathrm{N}-1$ times Formula 4 is shown below.

$$
\mathrm{P}_{\mathrm{s}}\left(\mathrm{t}_{0}\right)=\frac{\sum_{\mathrm{n}=1, \mathrm{t}=\mathrm{t}_{0}-\mathrm{N}}^{\mathrm{N}=1, \mathrm{t}=\mathrm{t}_{0}-1} \beta(\mathrm{n}) \mathrm{P}_{\mathrm{wp}}(\mathrm{t})}{\sum_{\mathrm{n}=1}^{\mathrm{N}-1} \beta(\mathrm{n})}
$$

The energy storage system throughput power reference value is shown in Formula 5.

$$
\mathrm{P}_{\text {bat }}(\mathrm{t})=\mathrm{P}_{\mathrm{s}}\left(\mathrm{t}_{0}\right)-\mathrm{P}_{\mathrm{wp}}(\mathrm{t})
$$

Type: $\mathrm{P}_{\text {bat }}(\mathrm{t})$ is the rated power of Wind-PV. $\mathrm{P}_{\mathrm{S}}\left(\mathrm{t}_{0}\right)$ is the smooth target reference at t0 time; $\mathrm{P}_{\mathrm{wp}}(\mathrm{t})$ is the actual Wind-PV. power at t time.

\section{Power grid volatility and Energy storage SOC balance index}

Power grid volatility is shown in Formula 6.

$$
\delta=\frac{\mathrm{P}_{\mathrm{wp}}(\mathrm{k})-\mathrm{P}_{\mathrm{b}}(\mathrm{k}-1)}{\mathrm{P}_{\mathrm{rat}}}
$$

Type: $\mathrm{P}_{\mathrm{wp}}(\mathrm{k})$ is wind power output for $\mathrm{k}$ moment; $\mathrm{P}_{\mathrm{b}}(\mathrm{k}-1)$ is Wind-PV-Energy storage output for k-1 time ; $\mathrm{P}_{\text {rat }}$ is the rate capacity of Wind-PV system.

Energy storage SOC balance index $\mathrm{M}(\mathrm{t})$ is shown in Formula 7.

$$
\mathrm{M}(\mathrm{t})=\frac{\mathrm{C}_{\text {soc }}(\mathrm{t})-\mathrm{C}_{\text {soc ref }}}{\left(\mathrm{C}_{\text {soc max }}-\mathrm{C}_{\text {soc min }}\right) / 2}
$$


Type: $\mathrm{C}_{\text {soc }}(\mathrm{t})$ is charged state of the energy storage system at time. $\mathrm{C}_{\text {soc ref }}$ is the reference value of SOC, $\mathrm{C}_{\text {soc ref }}=\left(\mathrm{C}_{\text {soc max }}+\mathrm{C}_{\text {soc min }}\right) / 2, \mathrm{C}_{\text {soc max }}$ and $\mathrm{C}_{\text {soc min }}$ is determined by according to the requirements of the energy storage system. Separately $C_{\text {soc } \max }=0.8, C_{\text {soc } \min }=0.2$. $M \in[-1,1]$, when the $M$ value is close to 1 , indicates the energy storage discharge ability stronger, the charging capacity is very low. When $\mathrm{M}$ is close to 1 , indicates the charging ability stronger, discharge ability is poor; If $\mathrm{M}$ the closer to 0 , indicates that energy storage charge and discharge capacity is moderate at this time. So we suggest to maintain $M$ value near 0 .

\section{Relationship of filter bandwidth, power volatility of accessing to grid and the output of energy} storage

For a Chinese Wind-PV demonstration unit history data(Capacity: Wind power is 99MW, PV power is $40 \mathrm{MW}$ ) Using 1 day power data to analysis complementary characteristics of power output fluctuation.

We use the method of improved weighted moving average self-adaptive filtering to smoothing control power of Wind-PV-Energy storage joint generation systems, and compared with traditional first-order low-pass filter smooth control strategies. Comparing the results is shown in Fig.1. Here filter bandwidth $\mathrm{T}=50$, the first-order low-pass filter time constant $\mathrm{T}=600 \mathrm{~s}$.

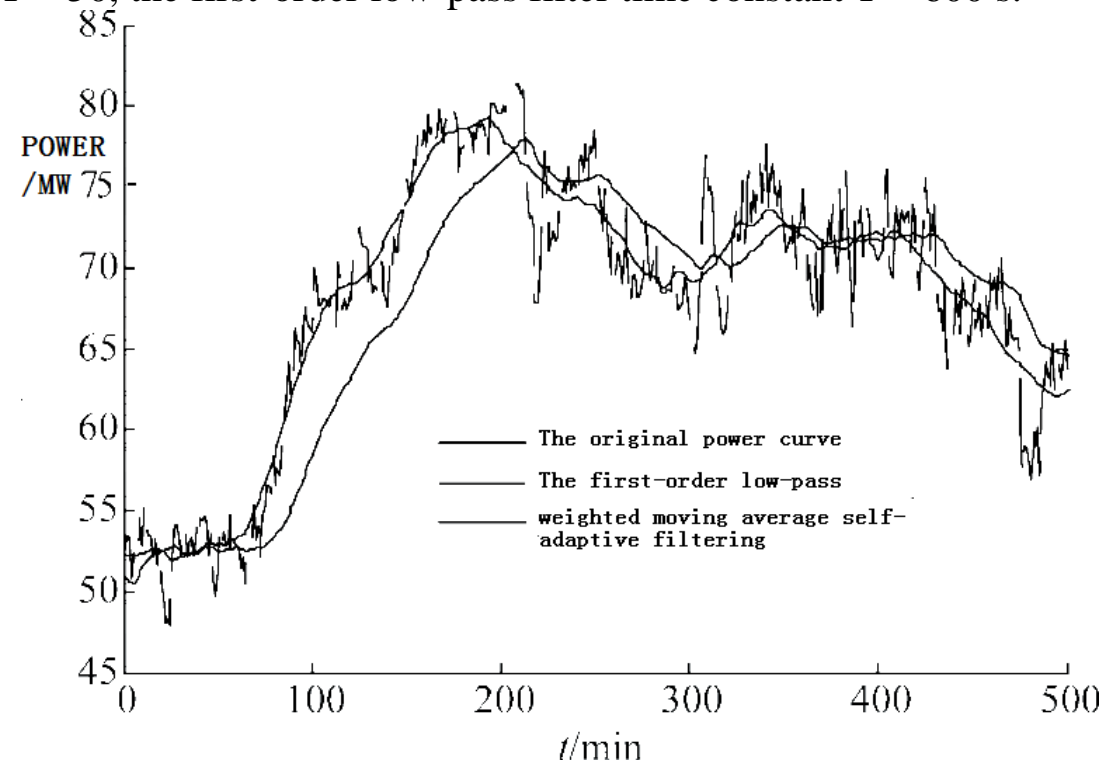

Fig.1 Wind-PV smoothing power curve under different filtering methods

See from Fig. 1. adaptive weighted moving average filtering method smoothing controlled output power and obtained the curve can better track the original curve than the first-order low-pass filtering. In order to further analysis of the relationship between the filter bandwidth and storage capacity, weighted moving average filtering bandwidth $\mathrm{T}$ respectively is taken by 10, 30, 50 . Wind-PV system smoothing effect and energy storage system energy curves are shown in Fig.2 and Fig.3.

Can be seen from the Fig.2 and Fig.3., with the weighted moving average filter bandwidth T value larger, Wind-PV-Energy storage joint generation systems synthesis output fluctuations gradually decreased, the effort of energy storage system stabilize Wind-PV system output power fluctuations is better. The corresponding energy storage maximum output power increases, the corresponding energy storage capacity required configuration also increase. Therefore filter bandwidth $\mathrm{T}$ is not only closely related to volatility of Wind-PV-Energy storage joint generation systems accessing to grid but also is closely related to the capacity of energy storage required. We need to add volatility constraints to the filtering algorithm. 


\section{Wind-PV-Energy storage system coordinated optimization control based on variable weight value self-adaptive filter}

The control strategy

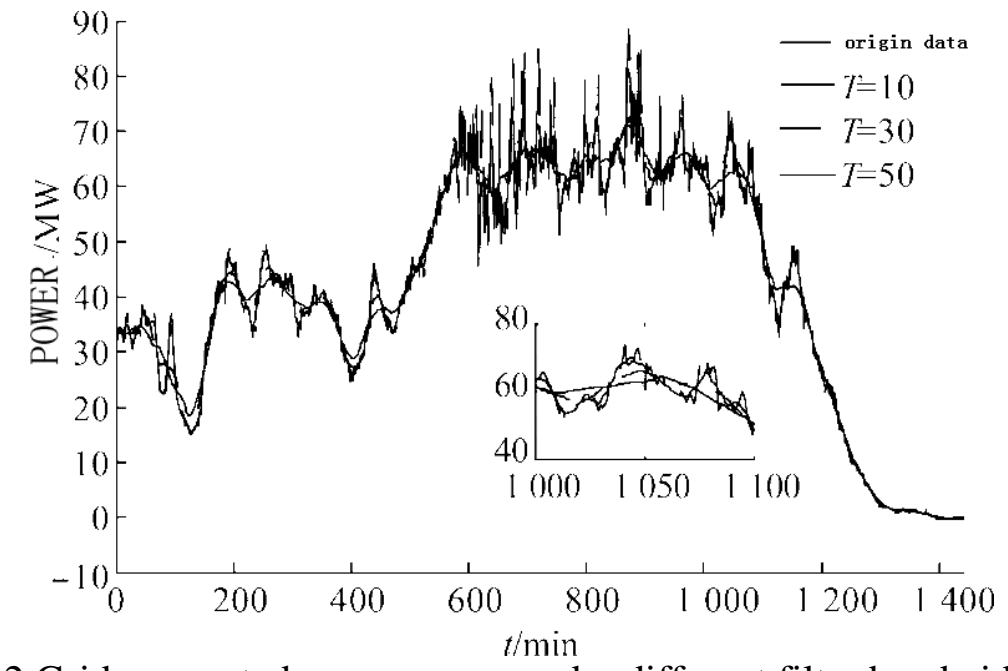

Fig.2 Grid connected power curve under different filter bandwidth $\mathrm{T}$

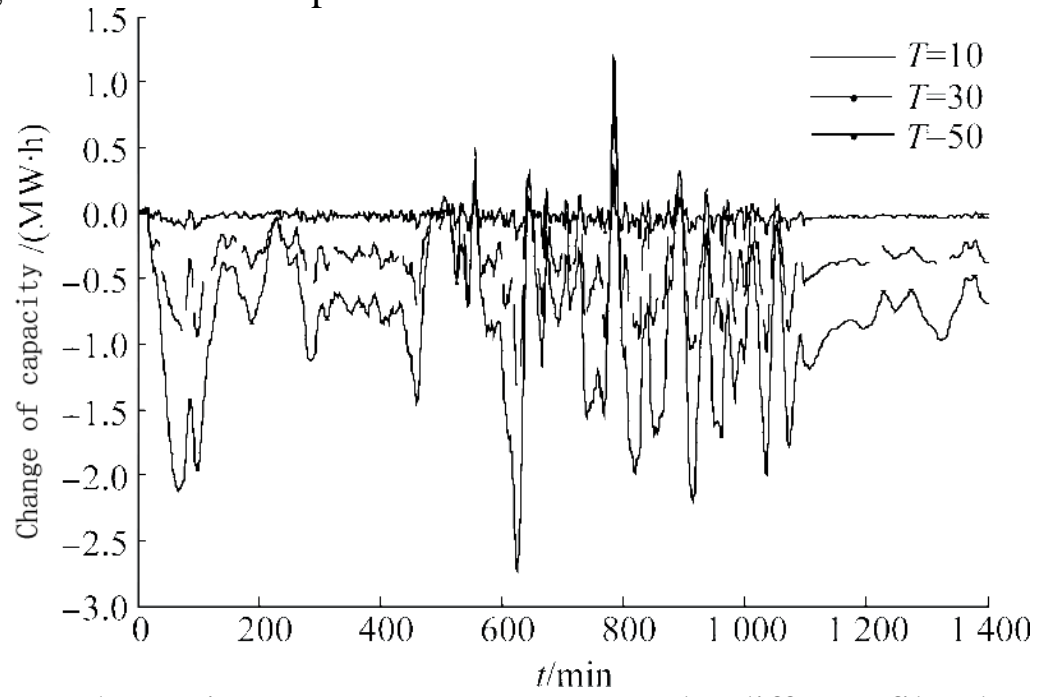

Fig.3 Energy change in energy storage system under different filter bandwidth $\mathrm{T}$

In full consideration $\mathrm{T}$ filter bandwidth, energy storage soc and volatility relations, the control strategy of Wind-PV-Energy storage system, considering the Wind-PV system volatility constraint conditions, reduced the energy storage output frequency and the using time, extended the service life of the energy storage system.

Wind-PV actual power data, which is in data acquisition system, input to The data acquisition system of wind power actual data input to weight value self-adaptive filter By calculating the volatility of wind power and the energy storage soc balance index , we real-time adjusting moving average weight and filter bandwidth $\mathrm{T}$, realize self-adaptive filter. Filter bandwidth $\mathrm{T}$, according to the energy storage system before the moment of energy storage SOC balance index ,real-time control energy storage output. In the process of smooth Wind-PV power, we limiting control energy storage power output in order to protect the energy storage system, to prevent the imitation discharge occurred which might affect the service life.

The steps of Wind-PV-Energy storage system coordinated optimization control based on variable weight value self-adaptive filter is shown at least.

i) Obtained Wind-PV power data through the data acquisition system, and calculated the volatility through the unit.

ii) If the volatility of wind power is greater than the set value, using variable weight value self-adaptive filter smooth control output and get the corresponding energy storage reference value 
$\mathrm{P}_{\text {bat }}$.

iii) If the volatility of wind power is less than the set value, the corresponding energy storage output is $0\left(\mathrm{P}_{\mathrm{bat}} .=0\right)$, Wind-PV joint generation system can access to grid indirectly.

iv) Get the grid power is $\mathrm{P}_{\mathrm{bat}}=\mathrm{P}_{\mathrm{s}}-\mathrm{P}_{\mathrm{wp}}$.

When the power is beyond the limit of its output power, energy storage is only allowed energy storage system with maximum rated energy storage power output, to ensure the safety of the energy storage system will not be allowed to occur hidden trouble of overloaded running.

\section{Optimization control Instance of volatility constraint of Wind-PV-Energy storage system}

The above proposed the method of variable weight value self-adaptive filter used to smooth control Wind-PV-Energy storage system output, with no volatility constraint condition smoothing effect were compared. The control results and volatility curves are shown in Fig.4 and Fig.5.

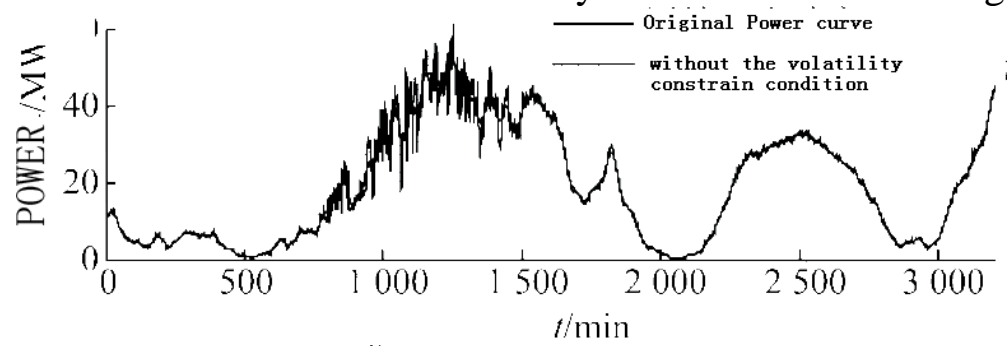

(a) without the volatility constrain condition

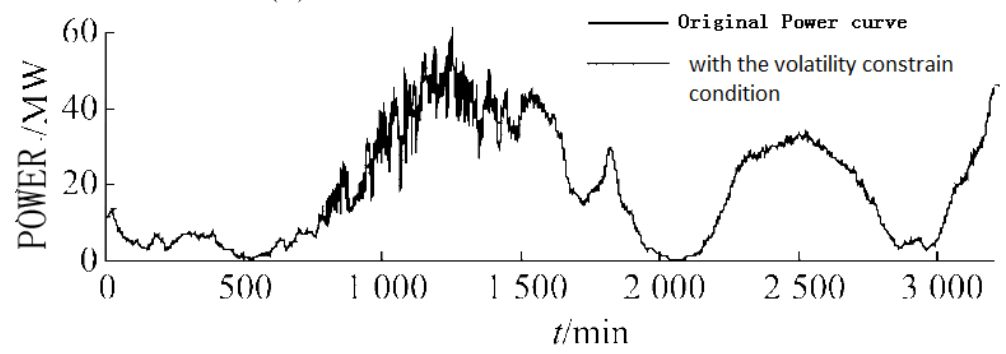

(b) with the volatility constrain condition

Fig.4 Wind-PV original/smoothing power with/without constraints
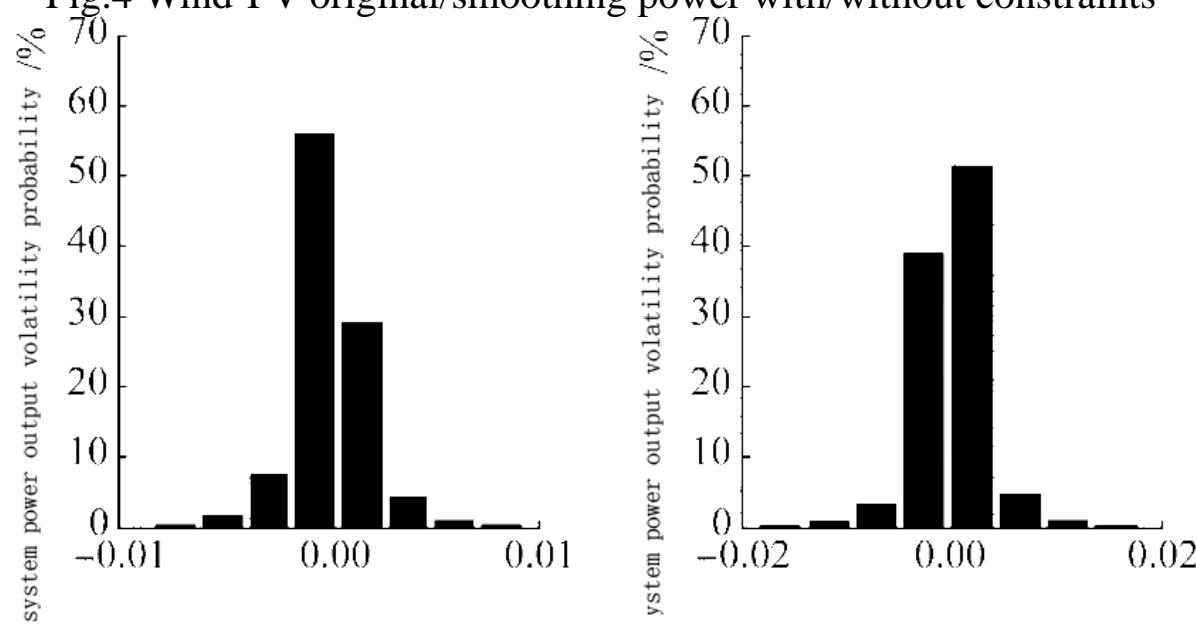

(a) without the volatility constrain conditior

(b) with the volatility constrain condition

Fig.5 Probability distribution per minute of wind-pv grid connected power volatility

Can be seen from the Fig.4 and Fig.5, without the volatility constrain condition, Wind-PV system power grid curve is smoother and less volatile after smooth control, system power output volatility probability per minute are mainly distributed in less than $1 \%$. With the volatility constrain condition, the probability distribution of volatility increases to $2 \%$, can satisfy the requirement of the wind power grid volatility restriction. Energy storage output, SOC and energy storage capacity curve are shown in Fig.6 to Fig.8.

As can be seen from the Fig.6, With the volatility constrain condition , energy storage system output time decreased significantly. Energy storage charge and discharge times decrease can prolong the service life of energy storage, but these two efforts showed that maximize and 
minimum output are the same. The maximize energy storage system output is $13.6793 \mathrm{MW}$, and the minimum is $-14.9897 \mathrm{MW}$.

From Fig.7 we can see that without the volatility constrain condition, the volatility range for SOC is [0.4550, 0.5427]. With the volatility constrain condition, the volatility range for SOC is [0.4278, 0.5151].

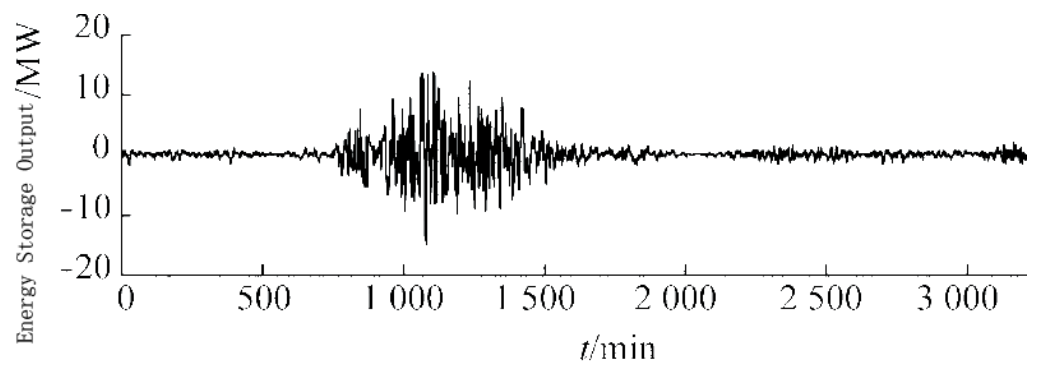

(a) without the volatility constrain condition

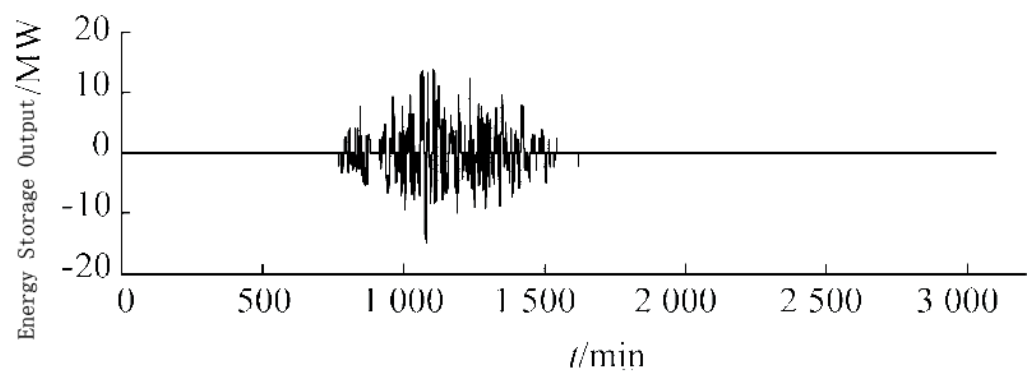

(b) with the volatility constrain condition

Fig.6 Energy storage system output with/without volatility constraints

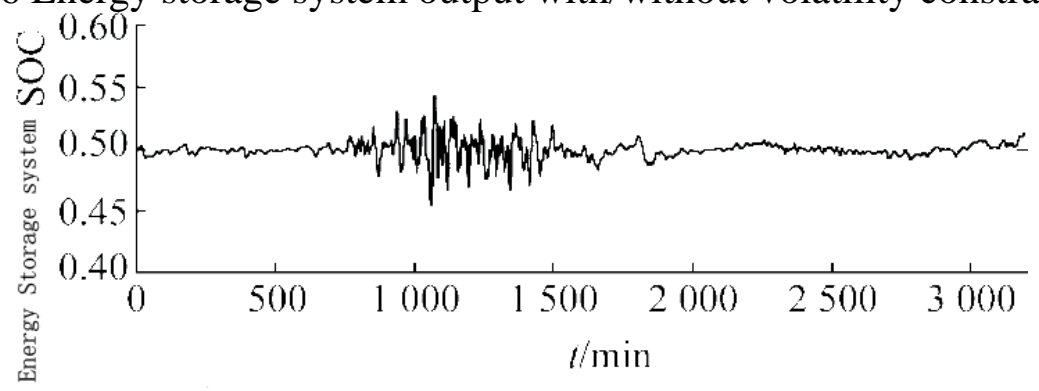

(a) without the volatility constrain condition

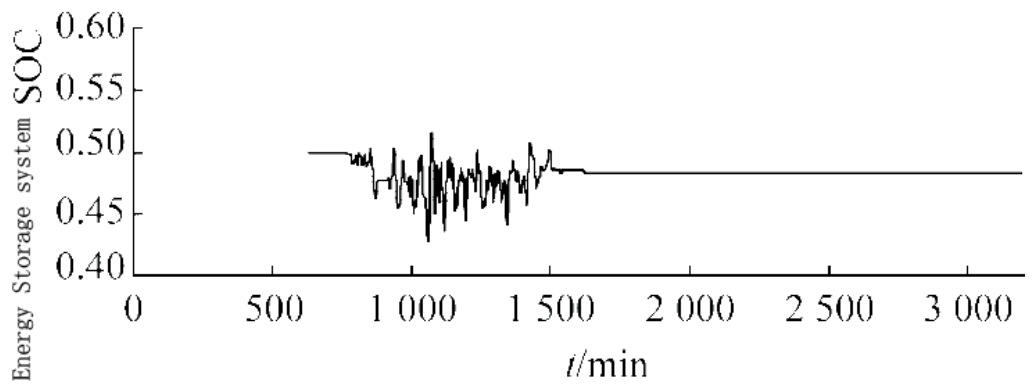

(b) with the volatility constrain condition

Fig.7 SOC comparison curves of energy storage system with/without volatility constraints

From Fig. 8 we can see that without the volatility constrain condition, the require capacity of configuring storage is $1.7524 \mathrm{MW} \bullet \mathrm{h}$, and With the volatility constrain condition, the require capacity of configuring storage is $1.7463 \mathrm{MW} \bullet \mathrm{h}$. The storage capacity required configuration reduces the $0.0061 \mathrm{MW} \bullet \mathrm{h}$, we reduce the cost of energy storage system.

\section{Conclusion}

This paper proposed Wind-PV-Energy storage coordinated control method based on variable weight self-adaption filter, considering the Wind-PV system volatility constraint conditions and the energy storage system SOC. It used energy storage coordinating the balance between Wind-PV 
system and grid, reduced the energy storage output frequency and the using time, extended the service life of the energy storage system, improved the economic benefit of Wind-PV-Energy storage joint generation systems. The SOC balance index can guarantee the operation of energy storage system surplus battery maintaining in a reasonable range, better use of energy storage system for tracking control Wind-PV system output, has certain engineering application value.

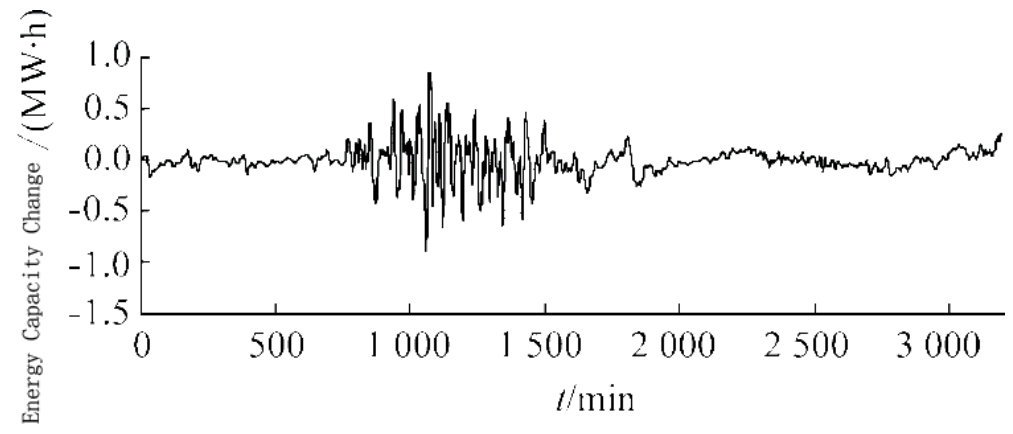

(a) without the volatility constrain condition

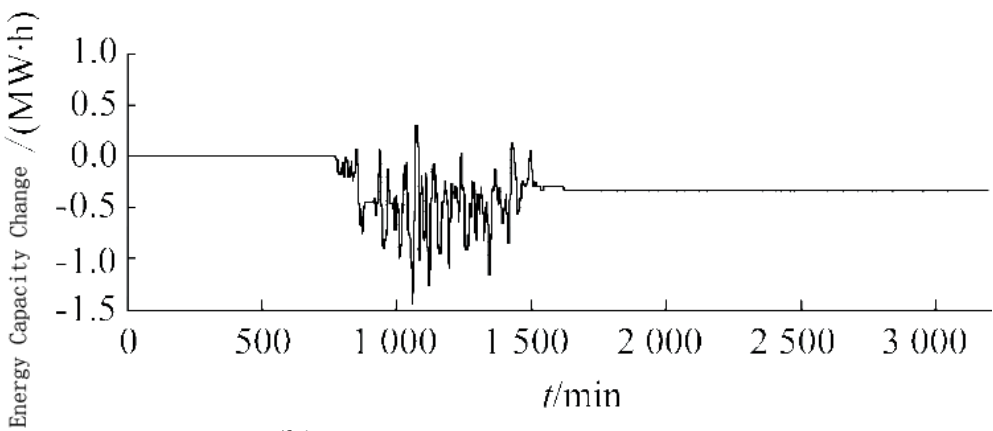

(b) with the volatility constrain condition

Fig.8 Energy change in energy storage system with/without volatility constraints

\section{References}

[1] Xu Juan, Sun Dawei. The smart grid-the best of all scheme to solve the bottleneck problems of wind power photoelectric power generation connected with power network on a large scale[J]. Ningxia Electric Power, Vol 1(2012):p 11-14.

[2] Yu Hang. Simulation research on smoothing the wind power fluctuation by using energy storage system[D]. Jilin: Northeast Dianli University, 2010.

[3] Li X J, Li Y, Han X J, et al. Application of fuzzy wavelet transform to smooth wind/PV hybrid power system output with battery energy storage[J]. Energy Procedia, Vol 12(2011):p 994-1001.

[4] Huang Ling, Cai Tao, Chen Tianjin, et al. Control strategy of battery energy storage system for large-scale pv system based on SOC adjustment[J]. Power system Protection and Control, Vol 41-16(2013):p 66-70.

[5] Qi Zhiyuan, Wang Shengtie, Tian Guizhen. Coordination control of wind/pv hybrid system[J]. Acta Energiae Solaris Sinica, Vol 5:p 654-660. 